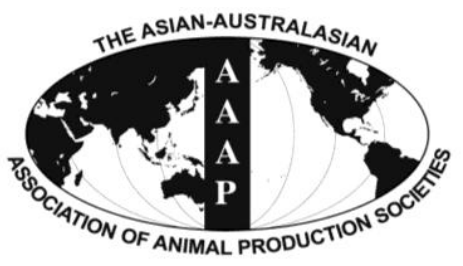

Open Access

Asian Australas. J. Anim. Sci.

Vol. 27, No. 9 : 1250-1253 September 2014

http://dx.doi.org/10.5713/ajas.2013.13797

www.ajas.info

pISSN 1011-2367 elSSN 1976-5517

\title{
Study on Growth Curves of Longissimus dorsi Muscle Area, Backfat Thickness and Body Conformation for Hanwoo (Korean Native) Cows
}

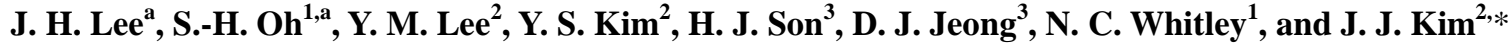 \\ Gyeongbuk Provincial College, Yecheon 757-807, Korea
}

\begin{abstract}
The objective of this study was to estimate the parameters of Gompertz growth curves with the measurements of body conformation, real-time ultrasound longissimus dorsi muscle area (LMA) and backfat thickness (BFT) in Hanwoo cows. The Hanwoo cows $(n=3,373)$ were born in 97 Hanwoo commercial farms in the 17 cities or counties of Gyeongbuk province, Korea, between 2000 and 2007. A total of 5,504 ultrasound measurements were collected for the cows at the age of 13 to 165 months in 2007 and 2008. Wither height (HW), rump height (HR), the horizontal distance between the top of the hips (WH), and girth of chest (GC) were also measured. Analysis of variance was conducted to investigate variables affecting LMA and BFT. The effect of farm nested in location was included in the statistical model, as well as the effects of HW, HR, WH, and GC as covariates. All of the effects were significant in the analysis of variance for LMA and BFT ( $<<0.01$ ), except for the HR effect for LMA. The two ultrasound measures and the four body conformation traits were fitted to a Gompertz growth curve function to estimate parameters. Upper asymptotic weights were estimated as $54.0 \mathrm{~cm}^{2}, 7.67 \mathrm{~mm}, 125.6 \mathrm{~cm}, 126.4 \mathrm{~cm}, 29.3 \mathrm{~cm}$, and $184.1 \mathrm{~cm}$, for LMA, BFT, HW, HR, WH, and GC, respectively. Results of ultrasound measurements showed that Hanwoo cows had smaller LMA and greater BFT than other western cattle breeds, suggesting that care must be taken to select for thick BFT rather than an increase of only beef yield. More ultrasound records per cow are needed to get accurate estimates of growth curve, which, thus, helps producers select animals with high accuracy. (Key Words: Hanwoo, Cows, Growth Curve, Ultrasound, Body Conformation)
\end{abstract}

\section{INTRODUCTION}

Hanwoo, a Korean native cattle (Bos taurus coreanae), was used for draft purpose in farms in South Korea. It has been about 30 years since selection programs to genetically improve yield and quality of Hanwoo meat were implemented (Park et al., 2013). Body weight was considered to be the most important trait in beef cattle to

\footnotetext{
* Corresponding Author: Jong-Joo Kim. Tel: +82-53-810-3027, Fax: +82-53-801-3027, E-mail: kimjj@ynu.ac.kr

${ }^{1}$ Department of Animal Sciences, North Carolina A\&T State University, Greensboro, NC 27411, USA.

2 School of Biotechnology, Yeungnam University, Gyeongsan 712-749, Korea.

${ }^{3}$ Gyeongbuk Livestock Research Institute, Yeongju 750-871, Korea.

${ }^{\text {a }}$ The authors contributed equally to this work.

Submitted Dec. 6, 2013; Revised Mar. 26, 2014; Accepted May 4, 2014
}

evaluate production ability. However, Hanwoo has slow growth rate and light mature weight, compared with other western well-known beef cattle breeds. Therefore, faster growth is a top priority in Hanwoo industry, as well as good meat quality and heavy weight (Lee et al., 2003a).

Biological characteristics of growth traits such as body structure or weight are measured at various ages. These records are considered as longitudinal data (Fitzhugh, 1976). Elucidation of growth characteristics has been a major interest in livestock research, because it would impact economic profit in Hanwoo industry (Lee et al., 2003a). Ulstrasound measurements such as longissimus dorsi muscle area (LMA), backfat thickness (BFT), and intramuscular fatness at early growth stage of Hanwoo individuals would provide optimal timing to sell in market or to keep for further feeding Hanwoo steers. Cow-calf producers can also use the techniques for reproduction or pregnancy determination.

Copyright $\odot 2014$ by Asian-Australasian Journal of Animal Sciences This is an open-access article distributed under the terms of the Creative Commons Attribution Non-Commercial License (http://creativecommons.org/licenses/by-nc/3.0/), which permits unrestricted non-commercial use, distribution, and reproduction in any medium, provided the original work is properly cited. 
Different methods were compared by Kim et al. (1996) to estimate growth curve parameters in Hanwoo. They reported that Gompertz and Richards models were better fit to real records. However, Gompertz model is easier to calculate than the Richards model that has one more parameter to be estimated and tends to overestimate time to reach $>70 \%$ maturity (Beltrán et al., 1992). Also, it has been reported that the Gompertz growth model was fitted better than other models for Hanwoo cows (Cho et al., 2006).

The objective of this study was to measure body conformation traits as well as ultrasound LMA and BFT in Hanwoo breeding stock (cows) in Gyeongbuk province, Korea, and to estimate the parameters of Gompertz growth curves.

\section{MATERIALS AND METHODS}

\section{Animals and phenotypic data}

The Hanwoo cows $(n=3,373)$ were born in 97 Hanwoo commercial farms in the 17 cities or counties of Gyeongbuk province, Korea, between 2000 and 2007. A total of 5,504 ultrasound measurements for LMA and BFT were collected mainly by one trained technician for the cows at the age of 13 to 165 months in 2007 and 2008. Each animal had 1.63 records on average due to limited labor and research environments. The LMA and BFT were measured between the 13th rib and 1st lumbar vertebrae with a Medicine (Ltd.) Pico v103 instrument (cm, 3.5 MHz linear array probe). Wither height (HW), rump height (HR), the horizontal distance between the top of the hips (WH), and girth of chest (GC) were also measured. The body conformation measurements were defined as in Choi et al. (2008).

\section{Statistical analyses}

Basic statistics such as mean, standard deviation were analyzed using SAS 9.2 (SAS Institute, Cary, NC, USA). Analysis of variance was conducted to investigate variables affecting LMA and BFT. The statistical model is shown in (1).

$$
\begin{aligned}
Y_{i j k}= & \mu+L F_{i j}+b_{1} H W_{i j k}+b_{2} H R_{i j k}+b_{3} W H_{i j k} \\
& +b_{4} G C_{i j k}+b_{5} A G E_{i j k}+e_{i j k}
\end{aligned}
$$

Where $Y_{i j k}$ is LMA and BFT of the kth cow at the jth farm within ith location, $L F_{i j}$ is the fixed effect of $j$ th farm within ith location, and $\mathrm{HW}, \mathrm{HR}, \mathrm{WH}, \mathrm{GC}$, and AGE are the covariate terms for height, rump height, the horizontal distance between the top of the hips, chest girth, and age at test, respectively. All of the effects of farm nested in location, $\mathrm{HW}, \mathrm{HR}, \mathrm{HD}$, and GC were significant in the analysis of variance for LMA and BFT ( $<<0.01)$, except for the HR effect for LMA (results not shown).

It has been reported that the Gompertz growth model was fitted better or computationally easier than other models for Hanwoo cows (Kim et al., 1996; Cho et al., 2006). Therefore, LMA, BFT, HW, HR, HD, and GC were fitted to a Gompertz growth curve function using SAS 9.2 (SAS Institute, USA) to estimate parameters as noted below (Tzeng and Becker, 1981);

$$
W_{t}=W_{0} \times e^{\left(\frac{m}{D}\right)\left(1-e^{-D \times t}\right)}
$$

where $W_{0}$ is the initial weight, $W_{t}$ is the weight at time, $t$, $m$ is the slope of growth curve when $t=0$ or the initial specific growth rate, and $D$ is the rate of exponential decay of the initial specific growth rate $m$, which measures rate of growth decline. Upper asymptotic weight $(A)$ when age $t$ approaches infinity is

$$
A=W_{0} \times e^{\left(\frac{m}{D}\right)}
$$

\section{RESULTS AND DISCUSSION}

Basic statistics are summarized in Table 1. The average age in months at which the measurements of ultrasound and body length were taken was $41.7 \pm 18.6$. The overall means of LMA, BFT, HW, HR, WH, and GC were $51.2 \pm 7.7 \mathrm{~cm}^{2}$, $5.13 \pm 2.64 \mathrm{~mm}, 124.1 \pm 4.6 \mathrm{~cm}, 125.3 \pm 4.3 \mathrm{~cm}, 28.2 \pm 2.7 \mathrm{~cm}$, and $179.2 \pm 10.3 \mathrm{~cm}$, respectively. Lee et al. (2008) reported greater LMA $\left(59.1 \mathrm{~cm}^{2}\right)$ and thicker BFT $(5.32 \mathrm{~mm})$ than the values in this study, but similar GC value $(178.7 \mathrm{~cm})$, when measured at $41.4 \pm 17.0$ months of age in the Hanwoo cows. Choy et al. (2011) reported greater LMA (54.1 \pm 9.1 $\mathrm{cm}^{2}$ ) and thinner BFT $(3.57 \mathrm{~mm})$ in a sample of Hanwoo cows than the results of this study. The differences between the results of the studies may be due to different ages at measurement or different feeding strategies among farms or regions.

Lee et al. (2003b) reported that Hanwoo cows had lower mature weight and later mature age than other breeds. Crews et al. (2004) reported that LMA and BFT in yearling

Table 1. Means, standard deviations (SD), minimum, maximum, and coefficients of variation $(\mathrm{CV})$ of ultrasound measures and body conformation traits

\begin{tabular}{lrccc}
\hline Trait & Mean \pm SD & Minimum & Maximum & CV \\
\hline LMA & $51.2 \pm 7.7$ & 29.4 & 95.4 & 15.0 \\
BFT & $5.1 \pm 2.6$ & 1.0 & 23.0 & 51.5 \\
HW & $124.1 \pm 4.6$ & 102.0 & 144.0 & 3.7 \\
HR & $125.3 \pm 4.3$ & 109.0 & 141.0 & 3.4 \\
WH & $28.2 \pm 2.7$ & 12.4 & 44.0 & 9.5 \\
GC & $179.2 \pm 10.3$ & 148.0 & 219.0 & 5.7 \\
\hline
\end{tabular}

LMA, longissimus dorsi muscle area $\left(\mathrm{cm}^{2}\right)$; BFT, backfat thickness (mm); $\mathrm{HW}$, height at wither $(\mathrm{cm})$; HR, height at rump $(\mathrm{cm})$; WH, horizontal distance between top of hips $(\mathrm{cm})$; GC, girth of chest $(\mathrm{cm})$. 
Table 2. Estimates of parameters in Gompertz growth curves of ultrasound measures and body conformation traits

\begin{tabular}{lcccccc}
\hline & LMA & BFT & HW & HR & WH & GC \\
\hline$W_{0}$ & $43.8 \pm 1.5$ & $3.3 \pm 0.2$ & $85.8 \pm 3.2$ & $73.2 \pm 6.9$ & $17.8 \pm 0.9$ & $133.9 \pm 3.3$ \\
$m$ & $0.008 \pm 0.002$ & $0.02 \pm 0.004$ & $0.04 \pm 0.01$ & $0.1 \pm 0.02$ & $0.04 \pm 0.01$ & $0.02 \pm 0.002$ \\
$D$ & $0.04 \pm 0.009$ & $0.02 \pm 0.005$ & $0.10 \pm 0.01$ & $0.1 \pm 0.01$ & $0.07 \pm 0.01$ & $0.07 \pm 0.004$ \\
\hline
\end{tabular}

LMA, longissimus dorsi muscle area $\left(\mathrm{cm}^{2}\right)$; BFT, backfat thickness $(\mathrm{mm})$; HW, height at wither $(\mathrm{cm}) ; \mathrm{HR}$, height at rump ( $\left.\mathrm{cm}\right)$; WH, horizontal distance between top of hips $(\mathrm{cm})$; GC, girth of chest $(\mathrm{cm}) ; W_{0}$, initial weight; $\mathrm{m}$, the slope of growth curve at the initial specific growth rate; $D$, the rate of exponential decay of the initial specific growth rate $m$, which measures rate of growth decline.

Simmental cows were $66.1 \mathrm{~cm}^{2}$ and $3.94 \mathrm{~mm}$, respectively. Roberts et al. (2007) reported that the averages of LMA and BFT for yearling crossbred cows (50\% Red Angus, 25\% Charolaise, and $25 \%$ Tarentaise) were $58.8 \mathrm{~cm}^{2}$ and 3.96 $\mathrm{mm}$, respectively. Pinheiro et al. (2011) reported that the average values of LMA and BFT in Nelore cattle were $48.98 \mathrm{~cm}^{2}$ and $1.94 \mathrm{~mm}$ at 20 months of age. Our results showed that the Hanwoo cows had smaller LMA and thicker BFT than other cattle breeds, although there was variability for the traits between individuals depending on genetics and feeding management, as would be expected.

The estimates of parameters in Gompertz growth curves for each ultrasound and body conformation traits were summarized in Table 2. Upper asymptotic weights were estimated as $54.0 \mathrm{~cm}^{2}, 7.67 \mathrm{~mm}, 125.6 \mathrm{~cm}, 126.4 \mathrm{~cm}, 29.3$
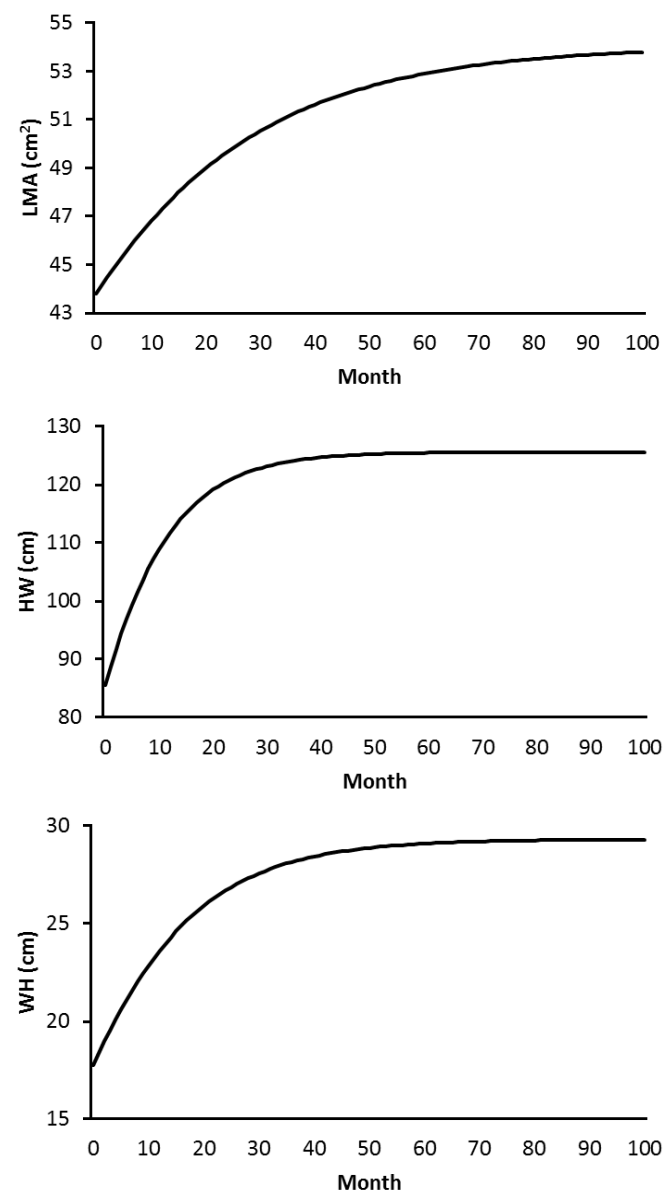

$\mathrm{cm}$, and $184.1 \mathrm{~cm}$, for LMA, BFT, HW, HR, WH, and GC, respectively. The estimates for 12 months of age were 47.3 $\mathrm{cm}^{2}, 3.93 \mathrm{~mm}, 111.7 \mathrm{~cm}, 114.3 \mathrm{~cm}, 23.6 \mathrm{~cm}$, and $159.4 \mathrm{~cm}$, respectively. Lee et al. (2008) reported that the estimates for asymptotic mature size of ultrasound LMA, BFT, and GC were $62.3 \pm 0.3 \mathrm{~cm}^{2}, 7.31 \pm 0.27 \mathrm{~mm}$, and $180.7 \pm 0.12 \mathrm{~cm}$ with Von Bertalanffy's growth function in a sample of Hanwoo cows for which the traits were measured between 2002 and 2007.

In this study, the upper asymptotic mature sizes (A) of HW and HR related to born growth reached at 35 to 40 months of cow age, while the A reached at later ages for other traits (Figure 1). The GC and WH that are related to reproductive performance had slower growth than HW and HR (Lee, 2011). The GC and WH also showed high Pearson
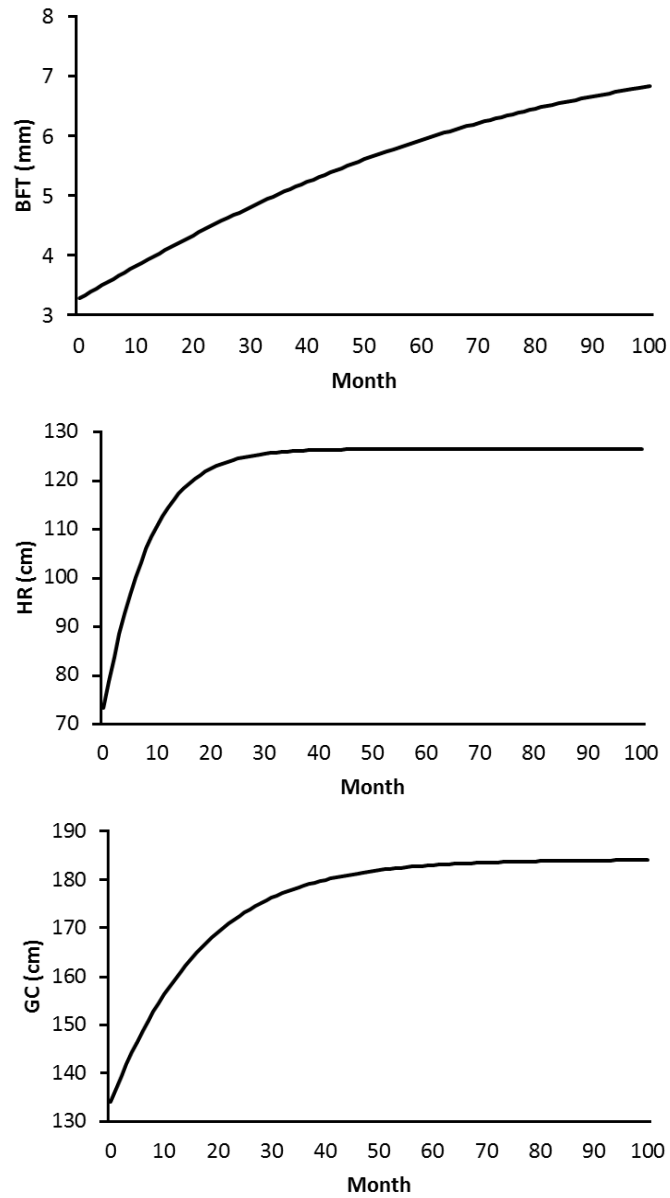

Figure 1. Gompertz curve for longissimus dorsi muscle area (LMA), backfat thickness (BFT), height at wither (HW), height at rump (HR), horizontal distance between top of hips (WH), girth of chest (GC). 
correlation $(0.66 ; \mathrm{p}<0.001)$ and reached A at approximately 60 months of age (Figure 1). Growth of LMA and BFT was much slower than $\mathrm{HW}, \mathrm{HR}, \mathrm{GC}$, and $\mathrm{WH}$, but the time to reach A of LMA was faster than for BFT. The LMA and GC also showed high correlation $(0.63 ; \mathrm{p}<0.001)$, which means that GC may be used to estimate LMA.

Data should be measured repeatedly from an individual to estimate accurate parameters for growth curves in Hanwoo cows. However, 1.63 records per individual are fairly low, but no study to estimate growth curve was reported with repeated ultrasound records in Hanwoo cows. Further studies should be done with records from 3 months to 24 months old before parturition having relatively smaller environmental effects.

Selection objectives in Hanwoo have been focused on growth or body shape, mainly due to small body size. Genetic improvements of beef yield haven been made by choosing individuals with heavier weights at a specific age, or even at earlier ages proper to a market standard weight (Cho et al., 2006). Both LMA size and BFT can be tracked easily using ultrasound measures, allowing for selection of breeding stock with optimal genetic improvement (Williams, 2002). However, more ultrasound records per cow are needed to get accurate estimates of growth curve, which, thus, helps producers select animals with high accuracy

\section{ACKNOWLEDGMENTS}

This research was supported by Bio-industry Technology Development Program, IPET, Ministry for Food, Agriculture, Forestry and Fisheries, Republic of Korea, 2013.

\section{REFERENCES}

Afolayan, R. A., W. S. Pitchford, M. P. B. Deland, and W. A. McKiernan. 2007. Breed variation and genetic parameters for growth and body development in diverse beef cattle genotypes. Animal 1:13-20.

Cho, K. H., S. H. Na, J. G. Choi, K. S. Seo, S. Kim, B. H. Park, Y. C. Lee, J. D. Park, and S. K. Son. 2006. Estimation of growth curve parameters and analysis of year effect for body weight in Hanwoo. J. Anim. Sci. Technol. (Kor.) 48:151-160.

Choi, T. J., K. Seo, S. Kim, K. H. Cho, J. G. Choi, I. H. Hwang, H. S. Choe, and C. J. Park. 2008. Estimation of Growth Curve Parameters for Body Weight and Measurements in Castrated Hanwoo (Bos taurus Coreanae). J. Anim. Sci. Technol. (Kor.) 50:601-612.

Choy, Y. H., J. K. Son, H. S. Kong, H. K. Lee, and K. D. Park. 2011. Estimation of genetic parameters for economic traits of Hanwoo cows using ultrasound. J. Anim. Sci. Technol. (Kor.) 53:505-509.
Crews, D. H., Jr., E. J. Pollak, and R. L. Quaas. 2004. Evaluation of Simmental carcass EPD estimated using live and carcass data. J. Anim. Sci. 82:661-667.

Fitzhugh, H. A., Jr. 1976. Analysis of growth curves and strategies for altering their shape. J. Anim. Sci. 42:1036-1051.

Gotoh, T., E. Albrecht, F. Teuscher, K. Kawabata, K. Sakashita, H. Iwamoto, and J. Wegner. 2009. Differences in muscle and fat accretion in Japanese Black and European cattle. Meat Sci. 82:300-308.

Kim, N. S., J. C. Joo, and D. H. Lee. 1996. Estimation of growth curve parameters in Hanwoo for system analysis. Korean $\mathrm{J}$. Anim. Sci. 38:119-124.

Lee, C. W., J. G. Choi, K. J. Jeon, K. J. Na, C. Lee, B. K. Yang, and J. B. Kim. 2003a. Estimation of growth curve for evaluation of growth characteristics for Hanwoo cows. J. Anim. Sci. Technol. (Kor.) 45:509-516.

Lee, C. W., J. G. Choi, G. J. Jeon, K. J. Na, C. Lee, J. M. Hwang, B. W. Kim, and J. B. Kim. 2003b. Estimation of parameters for individual growth curves of cows in Bos taurus Coreanae. J. Anim. Sci. Technol. (Kor.) 45:689-694.

Lee, D., G. Lee, C. Cho, and N. Kim. 2008. Effects of body condition score and estimation of growth curves for chest girth and ultra sonic longissimus muscle area, backfat thickness and marbling scores in Hanwoo (Korean cattle) cows. J. Anim. Sci. Technol. (Kor.) 50:581-590.

Lee, K. 2011. Estimation of Genetic Parameter for Linear Type and Conformation Traits in Hanwoo Cow. PhD Thesis, Chungnam University, Daejeon, Korea.

Menchaca, M. A., C. C. Chase, Jr., T. A. Olson, and A. C. Hammond. 1996. Evaluation of growth curves of Brahman cattle of various frame sizes. J. Anim. Sci. 74:2140-2151.

Park, B., T. Choi, S. Kim, and S.-H. Oh. 2013. National genetic evaluation (system) of Hanwoo (Korean Native Cattle). AsianAustralas. J. Anim. Sci. 26:151-156.

Pinheiro, T. R., M. E. Z. Mercadante, L. G. Albuquerque, J. N. S. G. Cyrillo, and R. H. Branco. 2011. Phenotypic and genetic parameters compared during repeated measures of longissimus muscle area and subcutaneous fat thickness in Nelore cattle. Genet. Mol. Res. 10: 2944-2952.

Roberts, A. J., S. I. Paisley, T. W. Geary, E. E. Grings, R. C. Waterman, and M. D. MacNeil. 2007. Effects of restricted feeding of beef heifers during the postweaning period on growth, efficiency, and ultrasound carcass characteristics. J. Anim. Sci. 85:2740-2745.

Tzeng, R. and W. A. Becker. 1981. Growth patterns of body and abdominal fat weights in male broiler chickens. Poult. Sci. 60:1101-1106.

Williams, A. R. 2002. Ultrasound applications in beef cattle carcass research and management. J. Anim. Sci. 80:E183-E188.

Yokoo, M. J., L. G. Albuquerque, R. B. Lôbo, L. A. F. Bezerra, F. R. C. Araujo, J. A. V. Silva, and R. D. Sainz. 2008. Genetic and environmental factors affecting ultrasound measures of longissimus muscle area and backfat thickness in Nelore cattle. Livest. Sci. 117:147-154.

Zhou, G. H., L. Liu, X. L. Xiu, H. M. Jian, L. Z. Wang, B. Z. Sun, and B. S. Tong. 2001. Productivity and carcass characteristics of pure and crossbred Chinese Yellow Cattle. Meat Sci. 58:359-362. 